\title{
Colorectal Serrated Adenocarcinoma
}

National Cancer Institute

\section{Source}

National Cancer Institute. Colorectal Serrated Adenocarcinoma. NCI Thesaurus. Code C96485.

A rare, invasive colorectal adenocarcinoma characterized by the presence of a malignant infiltrate with serrated glandular architecture. 